\title{
Challenges and Prospects of Enterprise Resource Planning (ERP) Systems in the Newly Chartered Public Universities in Kenya
}

\author{
Bett, Kipyegon Alfred \\ MBA, Bcom. \\ School of Business and Economics \\ University of Kabianga, Kericho, Kenya
}

\begin{abstract}
Enterprise resource planning (ERP) systems have been the most popular business management systems in the $21^{\text {st }}$ century, providing benefits of real-time capabilities, enhancing organizational competencies and seamless communication for business in both small and large organizations. Today, most universities have begun replacing their legacy systems with ERP initiatives to improve management and administration. Though they are credited with major prospects of re-engineering the work processes, these initiatives present some challenges to the management of these universities. This study focused on the challenges and prospects of ERP systems in the newly chartered public universities in Kenya. A review of previous studies on the challenges and prospects of putting in place this framework in public sector including universities was done. A descriptive survey research design was used to select the staff in all the 24 newly chartered universities in Kenya, while simple random sampling method was used in choosing 120 respondents who were heads of departments. A five point Likert scale questionnaire was used for data collection. A reliability estimate of 0.69 was realized for the instrument using Cronbach reliability coefficient. Data collected was analysed using descriptive statistics and presented in tables and charts. The study established that management support is vital for any organization to be able to successfully implement and use ERP systems effectively. In addition, inadequate preparation by the universities to manage change, failure to involve endusers during the implementation stage, failure by the system vendors to modify the system to conform to the requirements of these universities, failure by the institutions to re-engineer their business processes to match ERP requirements and lack of effective end-user training were also cited as the challenges facing the success of the ERP systems in the newly chartered universities. The findings further indicated successful implementation of the system will eliminate redundant tasks and lead to an overall reduction of operational cost. It will also lead to easier access to reliable data and information, improved customer relationship and the ability to produce better reports and information are some of the prospects that majority of the respondents believe the ERP system will provide. This study may be useful to public universities management by helping them gain better understanding on how to utilize information technologies. It also provides information that will assist them in making informed decisions on the best ERP implementation strategies to be employed. Lastly, the study will creates a forum for discussions on ways of solving ERP challenges currently being faced by the newly chartered public universities in Kenya.
\end{abstract}

Key Words: Enterprise Resource Planning, Prospects, Challenges, technology, Chartered, Investment

\section{Introduction}

A kind of information system known as Enterprise Resource Planning (ERP) is becoming more popular and useful in almost all industries specially in developing nations like Kenya.

ERP systems are application packages including several modules supporting all operation areas: planning, production, sale, marketing, distribution, accounting, financial, human resources, project management, stocks, service and maintenance, logistics and e-business. ERP software integrates and centrally manages the business functions of an organization (Buxbaum, 2001). Companies of all sizes and types have implemented 
ERP software packages to manage their organization, including public-sector organizations (Miranda, 1999). Public-sector organizations are unique because of additional government regulation and public accountability. Because ERP software is standardized for universal best business practices, it is sometimes difficult for public-sector organizations, such as Universities, to implement them (Harrison, 2004).

The rise in popularity of ERP software and the evidence of continued ERP implementation in the public sector make it important for University management to understand the challenges for implementing ERP software. Enterprise Resource Planning systems have transformed the way organizations go about the process of providing information. They promise to provide on-the-shelf solutions to the information needs of organizations. Despite that promise, implementation processes are plagued with much publicized failures and abandoned projects (Wairimu, 2011).

A number of studies have been carried out worldwide in an effort to address the challenges facing ERP systems as well as identify its prospects. These studies include Jepng'eno et al. (2016) who looked at the effects of ERP systems on organizational performance in Kitale technical training institute, Kenya. Mwove and Kwasira (2014) studied the effect of ERP system in enhancing service delivery in the procurement function in public universities in Kenya. Awad (2014) on one ERP system for twenty five Universities in Saudi Arabia. Hurbean (2008) investigated issues associated with implementation of ERP systems in the Public Administration. Lastly, Tortorella and Fries (2015) documented reasons for adopting an ERP system in a public university in Southern Brazil.

Available literature indicates that, so far, no study has attempted to address the challenges and prospects of ERP systems in the newly chartered public universities in Kenya, yet technology remains a key driver of business success in every industry.

The goal of the ERP system is to integrate all departments and functions across an organization onto a single computer based information system. This single system, according to Hossein (2004), is aimed at serving all the different departments within an organization depending on their particular needs. Some of the challenges that are faced by an organization when it is implementing an ERP are as associated with the mode of adoption by the organization. For example, Mehdi (2006) contrasts the benefits of full-fledged and partial adoption of ERP by an organization, he posits that when an organization implement a full-fledged ERP system, it may incur wasted resources due to the fact that ERP is a costly undertaking for any organization yet all its features may not be fully utilized (Ellen \& Bret, 2006).

\section{Statement of the Problem}

The wide spread penetration of IT has become a part of our social, business and economic fabric. Today, public universities in Kenya are looking for ways to integrate all their business processes in an effort to cut on operational costs, offer timely response to their clients and interact with their stakeholders' real time. To meet these requirements, public universities in Kenya have resorted to use of ERP systems to automate their operations on a standardized platform in line with their strategic plans. With most studies laying emphasis on ERP systems in big businesses in Kenya, this study seeks to establish the challenges and prospects of ERP systems in newly chartered public universities in Kenya. The principal aim of the study is to establish the Challenges and Prospects of Enterprise Resource Planning Systems in the Newly Chartered Public Universities in Kenya by seeking answers to the following question; what are the challenges and prospects associated with Enterprise Resource Planning (ERP) systems in the newly chartered Universities in Kenya?

\section{Significance of the Study}

This study is significant in several respects. First, the implementation of ERP software has continued to grow in both public and private universities in Kenya. Thus, it is important that the public Universities management have relevant information that will help them make intelligent decisions on the best initiatives. Secondly, it is also important for the public Universities management to understand the issues with which they could be faced during ERP implementation, based on that, this study provides information that will assist them in making informed decisions on implementation strategies.

Thirdly, the study will creates a forum for discussions on ways of solving ERP challenges currently being faced by the newly chartered universities in Kenya. 


\section{Enterprise Resource Planning Systems}

An Enterprise Resource Planning System (ERP) is an information system that manages, through integration, all aspects of a business including production, planning, purchasing, manufacturing, sales, distribution, accounting, and customer service (Scalle andCotteleer, 1999). In the past few years, ERP has become a "must have" system for many firms to improve competitiveness and efficiency. While it is possible to customise the ERP system to fit the organizational business processes, this is a contested area in both industry and academia: the current wisdom is that customisation is not recommended because of the high cost and problems with system upgrades and maintenance difficulties (Holland et al., 1999).

This study borrows the ERP definitions by David Caruso at Advanced Manufacturing Research, Incorporated and LaMonica as cited in Minahan (1998). Caruso describes ERP as "a transactional backbone" that gives organizations access to the information they need to make more knowledgeable decisions or to fuel more task specific applications, such as electronic commerce among other applications. Similarly, LaMonica (1999) defined ERP as the sharing of information among disparate systems to enable better decision making and increase operational speed. According to Miranda (1999), the following features are present in an ERP system: modular integration, which refers to different operational functions being tied together in an overall system; common and relational databases, which organize records into a series of tables linked by common fields.

Others are client/server technology, which is computer architecture wherein a server is networked to enduser desktop computers (clients) and drill down/audit trail capabilities, which refers to audit trails that provide the ability to review all of the history of changes to a record in the database (such as a requisition). ERP audit capabilities record activity by user name, date, time, and transaction. Drill-down permits the ability to reach the source document of a prior step in the process, such as detail for a journal entry. Features such as Flexible Chart-of-Accounts, which incorporates detailed information, while maintaining the overall reporting and budgeting structure; Advanced reporting and analysis, which equips decision makers with the tools to detect patterns and trends in order to make better decisions; Web enabling and internet capabilities, which facilitate transactions with the external world; Best business practices and process reengineering, which means that the software is modelled after best business practices and is also flexible enough to permit redesign of core operational processes; Workflow capabilities, which refers to the ability to push the flow of information through a business to the right people at the right point and Powerful development toolsets, which allow technical people to redefine menus and panels without changing the underlying programming codes are also included.

A number of studies have been done to assess the need for ERP systems in the academic industry in Kenya and beyond. Jepng'eno et al. (2016) study on the effects of ERP systems on organizational performance in Kitale technical training institute, documented that with the use of ERP systems, all financial transactions are more transparent since approvals through various levels are sought via the system and this helps management at various levels to know of any impending financial commitments as well as expenditures. This in essence enhanced accountability of all officers concerned in various functional areas. The findings also indicated that the use of ERP system has led to reduced duplication of records; this was realized since systems work with unique identifiers which once entered were available in the system across the organization in various modules.

Mwove and Kwasira (2014) on effect of ERP in enhancing service delivery in the procurement function in public universities in Egerton University established that ERP have significant relationship in enhancing service delivery in the procurement function. They recommended that since the implementation ERP systems require long-term planning for their success in improving the efficiency of the procurement function, the management has a great role to play in enhancing service delivery and also ensuring that personnel is trained on the implementation issues relating to the adoption and use of various systems for enhanced service delivery in the procurement function.

An empirical study on one ERP system for twenty five universities of Saudi Arabia Universities by Awad (2014) proves that ERP private cloud can be useful for any group of organizations that have same organization structure, data flow, business processes structure, and industry. He further posits that Saudi government should start thinking of providing ERP services to their public universities through the ERP 
private cloud to reduce the cost, better control on universities operations, and effective processes management.

Hurbean (2008) looked at issues with implementing ERP in the public administration. He documented that public sector organizations often rationalize their ERP modernization initiatives within the context of budgetary constraints and are faced with multiple ERP providers that, on the surface, are difficult to discern. In addition, adjudicating between competing ERP solutions on their functional merit is not only difficult because of the complexity of ERP systems, but it is further complicated by the intricacy of the government acquisition process. Therefore, it is particularly important that the business value be sold at the executive and political levels of government and, to be successful, that government embeds the ERP solution within its culture and processes.

Lastly, Tortorella and Fries (2015) looked at reasons for adopting an ERP system in a public University in Southern Brazil and documented that the University opted to develop its integrated internal systems and the results suggest that these reasons are similar to the reasons of other organizations, except those associated with the unique characteristics of those environments, such as the academic processes. It was found, however, that commercial ERP would be virtually incompatible with these organizations.

\section{Public Universities in Kenya}

A university's most valuable assets are faculty, programs and staff. Each has distinctive interests and characteristics within the same organization. For faculty, a university is a place to teach, conduct research, and write. For students, it is a place to learn, live, and entertain. For staff, it may share many features with corporate work, including management structure, hours, and human resources practices (Seo, 2013). (Duderstadt, Atkins \& Van, 2002) Pollock and Cornford (2004) stated that university is "thought of as a band of scholars coming together in pursuit and dissemination of knowledge, governed by a more or less collegiate model of organization, based around a complex structure of committees and with a high degree of individual and departmental autonomy". Considering the significant influence of information technology in universities, it is not surprising that many have adopted ERP systems for development and reengineering of administrative systems as a route to improved performance (King, 2002; Abugabah \& Sanzogni, 2010). This study looked at the newly chartered universities since they are still grabbling with a myriad of challenges including inadequate finances, poor infrastructural facilities and inadequate ICT staff.

\section{Challenges of ERP systems}

Bingi et al. (1999) stated, "The success of a major project like an ERP implementation completely hinges on the strong, sustained commitment of top management. This commitment, when percolated down through the organizational levels, results in an overall organizational commitment. An overall organizational commitment that is very visible, well defined and felt is a sure way to ensure a successful implementation". Thus, for successful ERP implementation, top management must be involved in every step. In addition, for successful implementation to occur, organizations must change the way they do business in order to align with the industry best practice as defined by the ERP vendor (Bingi et al. 1999). Organizations must carefully research and understand current business processes and how the processes will be handled using ERP systems. Jacobs and Bendoly (2003) points out that ERP should not simply be viewed as a technological artifact that assists organizations in fulfilling their tasks or as a productivity tool with a fixed output, rather it should be considered as a critical technological infrastructure that enhances the capabilities of all other tools and processes.

Many successful cases of ERP system implementation have been reported, but equally, many companies have announced their ERP systems as failed systems. The failure of ERP systems or the inappropriate usage of the systems will definitely cause a huge loss for the organization and may even lead to bankruptcy (Davenport, 1998; Soh et al., 2000; Chen, 2001; Davenport et al., 2004). For these systems to work they require substantial intellectual, material and managerial resources, a redesign of business processes and patterns of work flow, and a process of mutual adaptation of the system and organisational structure (Ke and Wei, 2008). In changing business structure and organisational structure, it could be a whole re-engineering process to avoid silos and systems that are not integrated. Policies and strategies might have to be written or modified to include the new structure. It will sometimes involve some staff being laid off and some new ones employed. A lot of retraining of staff also takes place. All these have to be done well for the 
implementation to be successful. In addition, ERP implementation involves many stakeholders; the project manager, project team members (employees from various business units), internal IT specialists, vendors and consultants.

The leadership as well as competence of these stakeholders will determine to a large extent the success of the project (Markus and Tanis, 2000). Lee and Lee (2000) have noted that it also includes multiple tasks such as software configuration, system integration, testing, data conversion, user training and system rollout. On the whole, ERP implementation is very complex and care needs to be taken at all the stages of implementation and after the system have gone live.

Heiskanen, Newman and Similä, (2000) suggest that ERP software, which incorporates best practices from the corporate business industry, is not appropriate for universities, since universities have unique structures and decision-making processes. Organizational culture heavily affects ERP implementation. Tsichritzis (1999) indicates that today's universities have been forced to admit that "education is a business and students are the customers". ERP implementation encourages universities take a more business-like approach to education, resulting in cultural changes including "the use of managerial language and techniques" (Allen, Kern and Havenhand, 2002). There can be resistance to ERP implementation at universities because it involves not merely the adoption of a new information system, but a holistic change in organizational culture. While there are diverse forms of management hierarchy from university to university, Birnbaum and Edelson (1989) describes that there exist two sources of authorities within a university: administrative authority and academic authority.

ERP implementation is believed to reinforce administrative authority as a model of governance. For academics, this may lead to fear that use of a new system that results in increased transparency of their transactions would result in a loss of control. On the other hand, administrative staff may fear for their job security when redundant processes are eliminated work functions are automated across a university (Allen $e t$ al., 2002). Moreover, Pollock and Cornford (2005) argue that ERP, as a "generic type of solution" from the corporate industry, could be a high-risk strategy for universities. Despite the need for unique business functions, ERP solutions limit the universities choices and encourage adopting a "generic solution". Since there have been few discussions and considerations regarding the challenges that universities might face from generic ERP system adoption, there is little assurance that the process will be successful.

Also, as ERP systems are "large integrated packaged solutions" with dynamic complexity, it may cause difficulties with implementation for management and IT staff in universities, even those who might have comprehensive understanding of their own organizations (Pollock \& Cornford, 2005). This is because universities have expanded a range of systems many of which have sometimes competing functions whenever they had particular needs (Pollock \& Cornford, 2005). In the worst case, universities do not always have management or IT staff who is well-versed in organizational functions. Standardization and integration, both of which are key features of ERP systems, limit flexibility in university systems. This loss of flexibility may lead staff to create 'workarounds' in which workers attempt to carry on their previous processes. This response to new ERP systems may ultimately increase staff workloads and create a data gaps between the system and reality.

\section{Prospects of Enterprise Resource Planning Systems}

Today's business environment is dramatically changing, competitive business environment, expanding markets, and rising customer expectations are some of the big challenges faced by most of the organizations. In the last few decades, globalization, scientific and technological advances of mankind influenced the educational institutions to consider the role of technology in educational processes (Hutinski and Aurer, 2009: 265-272). Private universities have long realized this need and, therefore, they have made huge investments in modern Information Systems (IS). In Kenya, public universities are not equipped with modern IS with the newly chartered public universities being the most poorly equipped technologically.

Several research studies have identified various prospects associated with ERP systems in organizations. O'Leary (2000) stated that an ERP system integrates the majority of the business processes and allows access to the data in real time. Furthermore, ERP improves the performance level of a supply chain by helping to reduce cycle times (Gardiner et al., 2002). There are also some intangible prospects that an organization may enjoy by implementing an ERP system including, better customer satisfaction, improved 
vendor performance, increased flexibility, reduced quality costs, improved resource utility, improved information accuracy and improved decision-making capability (Siriginidi, 2000).

The primary goal of ERP is to improve and increase information flow within an organization (Norris, Hurley, Hartley, Dunleavy, and Balls, 2000). Ideally, ERP software improves cooperation and interaction between all the business units in an organization payroll, personnel, purchasing, and inventory management among others. Integration allows the various departments to more easily share information and communicate with each other. Also, ERP software standardizes information within the organization. This streamlines the data flow between different parts of a business (Lieber, 1995). In an ERP system, data are entered by one department and staff in other departments immediately has access to the information without having to reenter the information into the system. Minahan (1998) stated "ERP gives all users a single, real-time view of their company's available resources and commitments". Public-sector organizations, such as school systems, may have specific requirements not applicable to private organizations. In addition, the cost of implementing an ERP system also may make it prohibitive for public-sector organizations to implement. According to Miranda (1998), if an ERP vendor only designs software for the public sector then he may not be following universal best business practices.

\section{Research Methodology}

The research study adopted a descriptive survey research design. Descriptive research design provide a comparative approach to the ERP systems in automating and integrating management practices of public universities in Kenya. This methodology also helped the researcher in using comparative statistical methods to analyse the research subject in the newly chartered public universities. The population for this study comprised all the heads of departments in all the 24 newly chartered public universities in Kenya. A simple random sampling technique was employed in the study. This method of sampling was chosen since it allows individuals to be chosen at random and not more than once to prevent a bias that would negatively affect the validity of the result of the experiment.

The research study relied on both primary and secondary data sources. Primary data was gathered using structured five point scale Likert questionnaire. In addition to the primary data, secondary data from journals, white-papers and e-books was also used to provide comparative perspectives to the study.

Validity and reliability was taken into consideration in the study in order to determine its objectivity, level of trustworthiness and credibility. This study made use of face validity where a panel of experts gave their input as to whether the instrument met the criterion while Cronbach's alpha $(\alpha)$ values were computed to test reliability where a score of more than 0.7 is considered acceptable. Scrutiny of the study by colleagues, peers and my supervisors was also used to gather and challenge assumptions made. Data was analysed using descriptive statistics, and factor analysis.

\section{Research Findings}

The researcher summarized the findings in line with the variables and objective of the study. This was followed by drawing of relevant conclusions. Lastly, recommendations for pertinent actions were suggested.

\section{ERP Challenges}

Respondents who worked in various departments were requested to give a rating on their level of agreement on ERP challenges in their departments. The variable had five indicators. The descriptive results are summarized and presented in Table 1. A scale of 1- 5 was used to measure the indicators where 1 strongly disagree and 5 represented strongly agree. 


\begin{tabular}{|c|c|c|}
\hline Indicators of ERP Challenges & $\mathbf{N}$ & Mean \\
\hline - The project had no skilled consultants. & 80 & 3.0000 \\
\hline $\begin{array}{l}\text { - The implementation project manager had no relevant } \\
\text { skills in project management. }\end{array}$ & 80 & 3.4000 \\
\hline - The project had no support of head of departments. & 80 & 3.0000 \\
\hline $\begin{array}{l}\text { - Top management was not kept abreast of the project } \\
\text { status. }\end{array}$ & 80 & 3.4500 \\
\hline - The organization was not prepared to manage change. & 80 & 3.6000 \\
\hline $\begin{array}{l}\text { - The project team was not knowledgeable about ERP } \\
\text { and business processes. }\end{array}$ & 80 & 3.3000 \\
\hline $\begin{array}{l}\text { End-users were never involved during the } \\
\text { implementation. }\end{array}$ & 80 & 3.6500 \\
\hline $\begin{array}{l}\text { - The implementation had no top management (executive } \\
\text { level) support. }\end{array}$ & 80 & 3.2500 \\
\hline - The ERP software was not modified to meet our needs. & 80 & 3.6400 \\
\hline $\begin{array}{l}\text { - There was no clearly defined scope for the } \\
\text { implementation project. }\end{array}$ & 80 & 3.2000 \\
\hline $\begin{array}{l}\text { - Our institution did not map or re-engineered our } \\
\text { business processes to match the ERP processes. }\end{array}$ & 80 & 3.9000 \\
\hline - There was no effective end-user training. & 80 & 3.6000 \\
\hline Aggregate & \multicolumn{2}{|c|}{3.4158} \\
\hline
\end{tabular}

Source: Survey Data (2018)

A mean score of 1 to 2.5 represented strongly disagree, 2.6 to 3.5 represented neutral while 3.6 to 5 represented strongly agree. According to the findings the following ERP challenges indicators had a mean of 3.6 and above meaning the respondents had a strong agreement with them.

- The organization was not prepared to manage change.

- End-users were never involved during the implementation.

- The ERP software was not modified to meet our needs.

- Our institution did not map or re-engineered our business processes to match the ERP processes.

- There was no effective end-user training.

This therefore indicates the challenges of ERP systems in the newly chartered universities are mostly due to inadequate preparation by these universities to manage change, failure to involve end-users during the implementation stage, failure by the system vendors to modify the system to conform to the requirements of these universities, failure by the institutions to re-engineer their business processes to match ERP requirements and lack of effective end-user training.

The ERP challenges indicators that had a mean greater than 2.6 and less than 3.6 shows that the respondents were neutral, that is they neither agreed nor disagreed. They are listed below:-

- The implementation project manager had no relevant skills in project management.

- The project had no skilled consultants. 
- The project had no support of head of departments.

- Top management was not kept abreast of the project status.

- The project team was not knowledgeable about ERP and business processes.

- The implementation had no top management (executive level) support.

- There was no clearly defined scope for the implementation project.

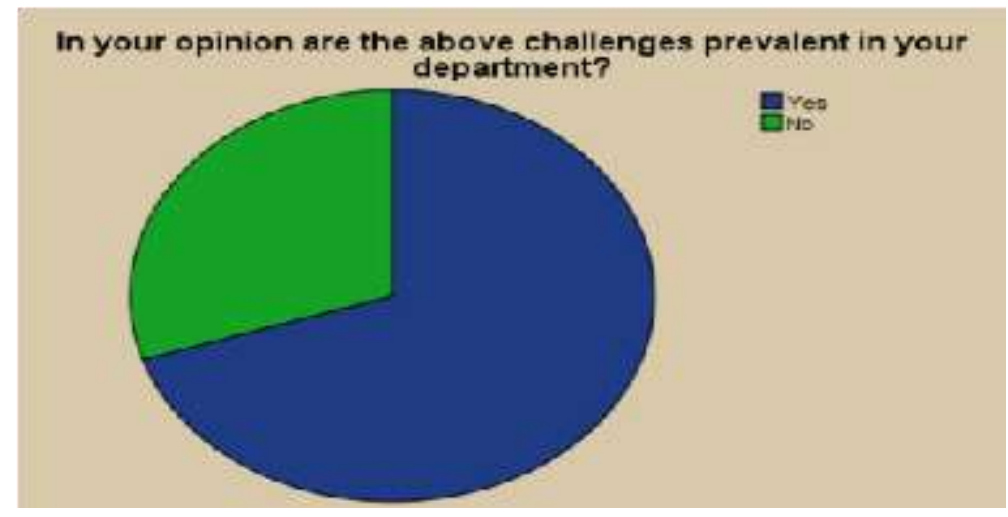

Figure 1: Opinion on ERP Challenges

Source: Survey Data (2018)

On the overall opinion of the respondents regarding ERP challenges, majority of them $70 \%$ as indicated in figure 1 agreed that the challenges are indeed prevalent in their departments.

\section{Enterprise Resource Planning (ERP) Prospects}

Similarly respondents were also requested to give a rating on their level of agreement on ERP prospects in their departments. The variable had five indicators. The descriptive results are summarized and presented in Table 2. A scale of 1- 5 was used to measure the indicators where 1 strongly disagree and 5 strongly agree.

\section{Table 2: ERP Prospects}

\begin{tabular}{lcc}
\hline Indicators of ERP Prospects & N & Mean \\
\hline - Eliminate/ Reduce redundant tasks. & 80 & 4.3000 \\
- Overall reduction of operational costs. & 80 & 3.3000 \\
- Redesign business processes. & 80 & 2.3000 \\
- Easier access to reliable data and information. & 80 & 3.7000 \\
- Improved customer relationship or supply chain & 80 & 4.2000 \\
- management. & 80 & 3.6000 \\
- Improve internal communication. & 80 & 3.9000 \\
- needed & 80 & 3.8000 \\
- Integration of all business processes in the university. & 80 & 3.7000 \\
\hline
\end{tabular}


Similarly on ERP prospects indicators, a mean score of 1 to 2.5 represented strongly disagree, 2.6 to 3.5 represented neutral while 3.6 to 5 represented strongly agree. According to the findings the following ERP prospects indicators had a mean of 3.6 and above meaning the respondents had strong agreement with them.

- Eliminate/ Reduce redundant tasks.

- Easier access to reliable data and information.

- Improved customer relationship or supply chain management.

- Improved internal communication.

- The ability to produce better reports and information needed

- Integration of all business processes in the university.

- Increase standardization of processes.

Majority of the of the respondents believe that the prospects associated with the ERP system will be realised, these are; elimination of redundancy, easier access to data and information, improved customer relationship or supply chain management, improvement of internal communication, ability to produce better reports and information needed, integration of all business processes and an increased standardization of processes.

The ERP prospects indicators that had a mean greater than 2.6 but less than 3.6 shows that the respondents were neutral, they neither agreed nor disagreed. They are listed below:-

- Overall reduction of operational costs.

- Redesign business processes.

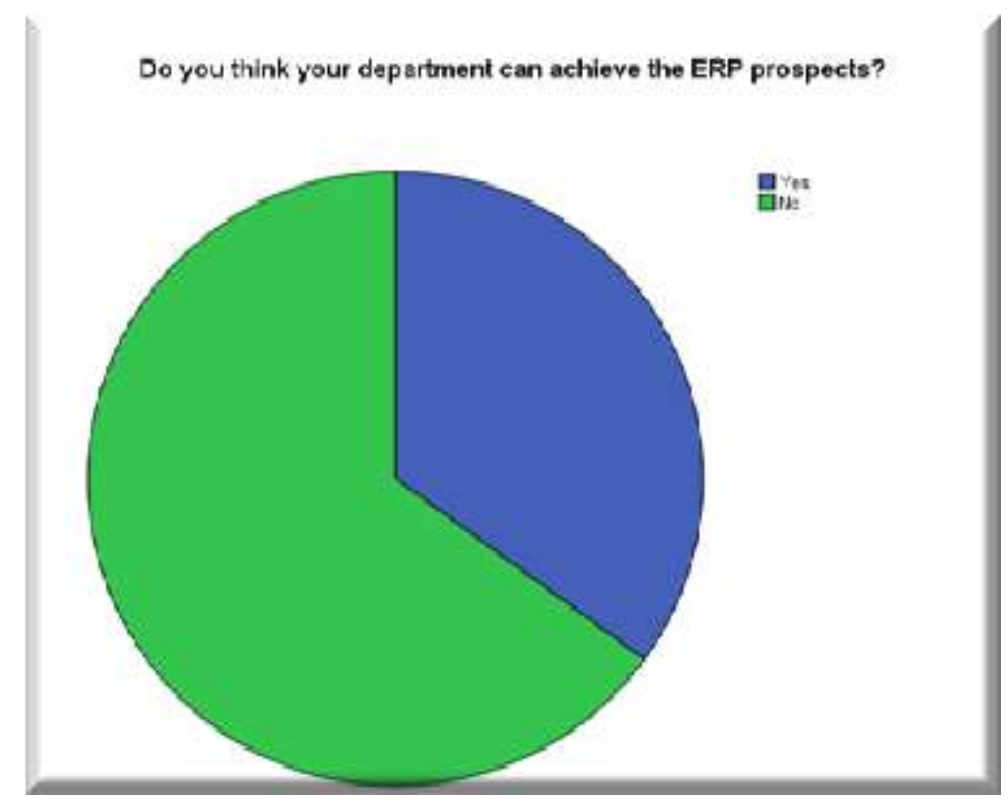

Figure 2: Opinion on ERP Prospects

Source: Survey Data (2018)

When the respondents were asked to give their overall opinion on whether the ERP prospects could be realised in the near future, only $40 \%$ of them believe so while majority $60 \%$ did believe in their departments achieving the prospects. 


\section{Summary}

This paper presents review of challenges and prospects of ERP system in the newly chartered universities in Kenya. The findings of this paper are based on analysis of both primary and secondary data. This research article highlights the challenges and prospects of ERP system in the context of developing nations like Kenya. All the universities studied were chartered lest than five years ago, meaning they are still struggling to stand on their own as fully fledged universities.

The university management and users can benefit from this study by identifying those key challenges to make the implementation procedure smooth without any disruption. Further ERP vendors can take inputs from this study to change their implementation approach. A well-designed and properly integrated and properly implemented ERP system allows the most updated information to be shared among various business units, thereby resulting in incredible cost savings and increased efficiency and provide competitive advantages. Of course, focussing and working on these challenges will improve the situation on successful ERP system implementation in public universities in Kenya.

The outcome provides important insights for the researchers and practitioners who are interested in implementing Enterprise Resource Planning systems, how best they can utilize their limited resources and to pay adequate attention to those factors that are most likely to have an impact upon the implementation of the ERP system. It also helps organizations to better understand the prospects of ERP systems and make the right decision on its investment.

\section{Conclusions}

The focus of the study was on the challenges and prospects of ERP systems in newly chartered public universities in Kenya. The study established that among the respondents, majority strongly agreed that management support is vital for an organization to be able to successfully implement and use an ERP system effectively. In addition, inadequate preparation by the universities to manage change, failure to involve endusers during the implementation stage, failure by the system vendors to modify the system to conform to the requirements of these universities, failure by the institutions to re-engineer their business processes to match ERP requirements and lack of effective end-user training were majorly cited as the challenges facing the success of the ERP systems in the newly chartered universities.

The findings further indicated that majority of the respondents agree that the system will eliminate redundant tasks and lead to an overall reduction of operational cost. Further, easier access to reliable data and information, improved customer relationship and the ability to produce better reports and information are some of the prospects that majority of the respondents believe the ERP system will provide.

\section{Recommendation for further Studies}

The research was focusing on the challenges and prospects of ERP systems in the newly chartered public universities in Kenya. The researcher recommends that similar or related studies should be conducted in other sectors of the economy to determine the challenges and prospects of ERP systems in those sectors. The study established that issues surrounding the implementation, user support and adoption of the right ERP solutions are complex and can be expensive. The study further recommended that more research should be conducted to clearly present measures that should be undertaken to encounter the challenges associated with implementation, management and use of these electronic solutions especially because the newly chartered university are still struggling to attract the best calibre of skilled professionals to run and manage their systems.

\section{References}

[1] Awad, H. (2014). One ERP System for twenty five Universities, an Empirical Investigation for Development ERP Private Cloud Kingdom of Saudi Arabia Universities Case. International Journal of Advanced Research in Computer and Communication Engineering 3(4), 22-40.

[2] Bingi, P., Sharma, M., \& Godla, J. (1999). Critical issues affecting an ERP implementation [Electronic version]. Information Systems Management, 16(3), 7-13. Retrieved on April 21, 2002, from the Business Source Premier database via the World Wide Web.

[3] Birnbaum, R., \& Edelson, P. J. (1989). How colleges work: The cybernetics of academic organization and leadership. The Journal of Continuing Higher Education, 37(3), 27-29. 
[4] Duderstadt, J. J., Atkins, D. E., \& Van Houweling, D. E. (2002). Higher education in the digital age: Technology issues and strategies for American colleges and universities Praeger Pub Text. USA

[5] Gardiner, S.C., Hanna, J.B. \& LaTour, M.S. (2002). 'ERP and the re-engineering of industrial marketing processes: a prescriptive overview for the new-age marketing manager'. Industrial Marketing Management, 31, 357-365.

[6] Heiskanen, A., Newman, M., \& Similä, J. (2000). The social dynamics of software development. Accounting, Management and Information Technologies, 10(1), 1-32. doi:10.1016/S09598022(99)00013-2

[7] Holland, C., Light, B. \& Kawalek, P. (1999). Beyond Enterprise Resource Planning Projects: Innovative Strategies for Competitive Advantage. Proceedings of the $7^{\text {th }}$ European Conference on Information Systems, 1, 288-301.

[8] Hurbean, L. (2008). Issues with Implementing ERP in the Public Administration. Retrieved from http://mpra.ub.uni-muenchen.de/14160/

[9] Hutinski, Z. \& Aurer, B. (2009). "Informacijska i komunikacijska tehnologija u obrazovanju: stanje i perspective." Informatologia, 42, 265-272.

[1] Jacobs, F.R., \& Bendoly, E. (2003). Enterprise resource planning. Developments and directions for operations management research, 1, 233-240

[2] Jepng'eno, M., AmuhayaIravo, M.,\& Sakataka, W. (2016). Effects Of Enterprise Resource Planning Systems on Organizational Performance in Kitale Technical Training Institute, Kenya. Journal of Business and Management, 18(9), 110-116.

[3] Ke, W., \& Wei, K. K. (2008). Organizational culture and leadership in ERP implementation. Decision Support Systems, 45, 208-218.

[4] King, P. (2002). The promise and performance of enterprise systems in higher education. EDUCAUSE Quarterly, 4(2), 6-14

[5] LaMonica, M. (1999 August 16). Life after ERP: Ebusiness shakes up the manufacturing industry with a push of optimization and supply-chain integration [Electronic Version]. InfoWorld, 21(33), 24. Retrieved July 12, 2002.

[6] Lee, Z., \& Lee, J. Y. (2000). An ERP implementation case study from a knowledge transfer perspective. Journal of Information Technology, 15(4), 281-288.

[7] Lieber, R. (1995). Here comes SAP. Fortune, 132(7), 122(3). Retrieved June 3, 2002.

[8] Markus, M. L., \& Tanis, C. (2000). The enterprise system experience-From adoption to success. In R. W. Zmud, Framing the domains of IT management research. Cincinnati, OH: Pinnaflex.

[9] Minahan, T. (1998). Enterprise Resource Planning [Electronic Version]. Purchasing, 125,112-120. Retrieved June 3, 2002.

[10] Miranda, R. (1999). The rise of ERP technology in the public sector. [Electronic Version]Government Finance Review, 9(8). Retrieved July 12, 2002 from WilsonSelectPlus.

[11] Mwove, R., \& Kwasira, J. (2014). Effect of Enterprise Resource Planning in Enhancing Service Delivery in the Procurement Function in Public Universities in Kenya, A Case study of Egerton University- Njoro, Kenya. International Journal of Science and Research 3(10), 4-16

[12] Norris, G., Hurley, J. R., Hartley, K. M., Dunleavy, J. R., \& Balls, J. D. (2000).E-Business and ERP: Transforming the enterprise. New York: John Wiley \& Sons, Inc.

[13] O'Leary, D. (2000). Enterprise Resource Planning Systems: Systems, Life Cycle, Electronic Commerce, and Risk. New York: Cambridge University Press,

[14] Pollock, N., \& Cornford, J. (2004). ERP systems and the university as a "unique" organisation. Information Technology \& People, 17(1), 31-52.

[15] Pollock, N., \& Cornford, J. (2005). Implications of enterprise resource planning systems for universities: An analysis of benefits and risks. International Journal of Computing Academic Research (IJCAR) 4(5),265-269

[16] Rogers, E.M. (1995). Diffusion of innovations (4th ed.). New York: The Free Press

[17] Scalle, C. X., \& Cotteleer, M. J. (1999). Enterprise resources planning (ERP). Boston: Havard Business School Publishing.

[18] Siriginidi, S.R. (2000). 'Enterprise resource planning in re-engineering business', Business Process Management Journal, 6(5), 376-91. 
[19] Tortorella, G., \& Fries, E. (2015). Reasons for Adopting an ERP System in a Public University in Southern Brazil. Proceedings of the 2015 International Conference on Operations Excellence and Service Engineering Orlando, Florida, USA.

[20] Tsichritzis, D. (1999). Reengineering the university. Communications of the ACM, 42(6), 93-100. 